\title{
Identidades de género y Feminismo: Su relación con la visión del Sumak Kawsay ${ }^{1}$
}

\author{
Gender Identities and Feminism: Their \\ Relation to the Sumak Kawsay Vision
}

Natalia Mahecha Valles* Brian Latorre González**

\section{Resumen}

El sumak kawsay es un concepto abstracto y cambiante, cuyas propuestas se han posicionado como claves para la creación de un desarrollo alterno al establecido por la modernidad. Se opone directamente a aquellas prácticas neoliberales que permiten un capitalismo salvaje y un consumo acelerado, haciendo por tanto resistencia a estructuras de poder colonizadas. Las identidades de género y feminismos surgen bajo ese mismo ámbito de resistencia a la modernidad y las estructuras de poder, aportando una mirada decolonial al discurso de desarrollo. En ese sentido, este artículo de investigación busca establecer si los discursos de género y sus transformaciones, y los feminismos, particularmente los decoloniales, comunitarios y

1 Artículo de revisión.

* Politóloga, con diplomado en Arte y comunicación visual de la Universidad de San Buenaventura, sede Bogotá, graduada con trabajo de grado con mención meritoria.

** Politólogo, con diplomado en Arte y comunicación visual de la Universidad de San Buenaventura, sede Bogotá, graduado con trabajo de grado con mención meritoria. 
marxistas, pueden ser entendidos o enmarcados como un elemento del sumak kawsay.

\section{Palabras clave}

Sumak kawsay, colonización, descolonización, feminismos, género.

\section{Abstract}

The sumak kawsay is an abstract and changing concept, whose elements have been positioned as keys to the creation of a development alternative to that proposed by modernity. It is directly opposed to those neoliberal practices that allow for savage capitalism and accelerated consumption, by resisting colonized power structures. Gender identities and feminisms emerge under the same context of resistance to modernity and power structures, bringing a decolonial look to the development discourse. In this sense, this research article seeks to establish whether gender discourses and their transformations, and feminisms, particularly decolonial, communitarian and Marxist ones, can be understood or framed as an element of Sumak Kawsay.

\section{Key words}

Sumak kawsay, Colonization, Feminisms, Gender.

\section{Introducción}

Las visiones, cosmovisiones y costumbres son elementos constitutivos de cualquier cultura perteneciente a una nación. Las tradiciones latinoamericanas han estado marcadas por las visiones de las comunidades indígenas a partir de lo místico y lo sagrado; sin embargo, los procesos de colonización trataron de extinguir estas 
cosmovisiones, reemplazándolas por nuevos misterios y estableciendo nuevas sacralidades. La historia da cuenta de ello.

En países de Latinoamérica persisten gran cantidad de comunidades indígenas; solo en Colombia existen 102 comunidades que preservan sus costumbres y visiones ancestrales; sin embargo, a pesar de la masividad de comunidades indígenas en el continente, algunos países sobresalen por la dinámica política, social y cultural de sus comunidades indígenas. Un ejemplo de esto es Bolivia y Ecuador, países en los que el sumak kawsay y el sumak qumaña, ambos elementos importantes de las comunidades indígenas empiezan a tener relevancia como filosofía y forma de vida. La diferencia de estos dos conceptos reside en que cada uno proviene de un idioma nativo diferente, pero en grandes términos significan lo mismo, una forma de vida integral para alcanzar un bienestar pleno, pero nos dan muestra de que existen diferentes formas de vidas, y como lo expondremos más adelante, múltiples buenos vivires.

El sumak kawsay se ha presentado como una propuesta de vida integral que, como lo mencionamos anteriormente, ha nacido a partir de las cosmovisiones indígenas, propendiendo por un respeto hacia la naturaleza; esta propuesta pretende retomar culturalmente prácticas armónicas con los demás seres vivos, evitando la explotación capitalista y occidental en los países, sobre todo latinoamericanos. Esta propuesta que se presenta como un debate ya se ha introducido en las constituciones de Bolivia y Ecuador, bajo las cuales el capitalismo es una teoría que representan un mal desarrollo, pues se basa en la competencia entre individuos y un "desarrollo" a costa de todo y todos. Por ello, el buen vivir es la salida del capitalismo salvaje, nos regresa a la vida en comunidad sin dañar a otros. Los avances en Ecuador de brindar a la naturaleza derechos es un avance sustancial para retomar una cultura no occidental del consumo excesivo de bienes materiales. 
Por otro lado, en ese mismo camino del reconocimiento de los derechos de la naturaleza sobresale la sentencia de la corte constitucional de Colombia en la que, bajo una lucha por las economías ilegales, le otorga reconocimiento legal al río Atrato, además de proporcionar visibilidad por medio de la participación para el cuidado del río a las comunidades históricamente relegadas que dependen del río como fuente de vida. Si bien esta sentencia puede interpretarse como una reivindicación social para comunidades vulnerables, el objeto de fondo que resuelve es el reconocimiento del río como sujeto de derechos, por lo que debe ser protegido por un Estado de derecho y sus instituciones (Sentencia T-622 de 2016).

Otro punto importante de reflexión que permite este fallo constitucional es que, como lo manifiestan Laura Pérez Prieto y Mónica Domínguez-Serrano (2015), al otorgar un reconocimiento jurídico de la Naturaleza como sujeto de derechos se ha superado el enfoque jurídico clásico por el que la conservación del medio ambiente es entendida simplemente como un derecho de las personas a gozar de un entorno sano y no contaminado y se ha pasado a aplicar otros criterios de justicia no individuales ni exclusivamente humano. (2015).

Conjuntamente, Alberto Acosta (2011) considera importante estudiar la constitución de Montecristi, Ecuador, para el debido entendimiento del buen vivir y la aplicación de normas constitucionales amigables con la filosofía sumak kawsay. Esta constitución se desarrolla principalmente en dos campos de acción, régimen del buen vivir y régimen de desarrollo, en los cuales existe una interrelación en tanto se crean mecanismos dentro del régimen de desarrollo como: "el conjunto organizado, sostenible y dinámico de los sistemas económicos, políticos, socioculturales y ambientales, que garantizan la realización del Buen Vivir, del Sumak Kawsay” (art. 275, Constitución). Entonces, está claro que la constitución de Montecristi logra vincular el concepto de desarrollo con el buen vivir; en tanto que 99 artículos de 444 están enfocados en esta filosofía, además de que es 
nombrada repetidas veces, pero el autor aclara que, aunque estos dos conceptos alternativos se vinculen en la Constitución, la "conquista" del buen vivir requiere unas transformaciones sustanciales en las estrategias de desarrollo.

Vemos, entonces, cómo el papel político de las diversas comunidades indígenas ha logrado posicionar la cosmovisión del sumak kawsay en la transformación de la política tradicional y neoliberal, que ha constituido una idea lineal de desarrollo económico, social y cultural. Una primera conclusión es que se presenta como una alternativa de vida proveniente de las concepciones de las comunidades indígenas latinoamericanas, pero que es, a su vez, un concepto que se transforma y presenta alternativas y oposiciones a estructuras de poder colonizadas (para objeto de este artículo: lograr relacionar los temas de género con el sumak kawsay, tomaremos como ejemplo estructuras heteropatriarcales y relacionadas al género).

Entonces, a partir de las experiencias boliviana y ecuatoriana, el sumak kawsay se asume en este proyecto no como una propuesta político institucional, sino como una filosofía de vida, una práctica de vida buena que surge desde lo local, desde las condiciones locales, buscando armonía con la comunidad y con el territorio. Así, es claro que los discursos de buen vivir son pluralistas, parten de la particularidad de los discursos existentes y no son una ruptura radical con discursos y prácticas anteriores. No puede haber un concepto dominante de buen vivir, ni tampoco un buen vivir limitado a comunidades indígenas, así se alimenten de sus prácticas y enseñanzas.

En ese sentido el concepto del sumak kawsay en un planteamiento abstracto, diverso y complejo que parte de una autonomía territorial; el sumak kawsay surge de lo local y se construye a partir de concepciones y prácticas comunitarias. De tal forma, está vulnerable a nuevas expresiones o entendimientos de lo que se percibe a partir de este concepto. A pesar de esto, estas transfor- 
maciones van a estar cimentadas en una naturaleza firme y ceñida del sumak kawsay: un discurso (filosofía) que hace resistencia a un modelo neoliberal cimentado en un capitalismo salvaje y de consumo acelerado; hace resistencia además a estructuras de poder colonizadas. Las comunidades indígenas de Bolivia son de gran importancia en la transición del sumak kawsay como cosmovisión a una transformación como concepto, filosofía y forma de vida. A partir de la llegada de Morales, se emprendieron reformas políticas que le permitieron la inclusión en la toma de decisiones de movimientos indígenas y campesinos, los cuales históricamente habían estado relegados en la estatalidad boliviana, a pesar de su gran mayoría. Debido a las movilizaciones y acciones como rechazo a las políticas neoliberales que estaban desarrollando sus países; a través de las movilizaciones lograron la creación de una constitución que comprende a Bolivia como un Estado pluralista.

A partir de esto, el sumak kawsay se presenta como una forma de repensar el desarrollo económico, social, político y cultural, que ha estado atravesado por dinámicas colonizadoras en las estructuras de poder. Por medio de procesos de globalización y modernidad, se han implementado dinámicas de exclusión que favorecen procesos de colonización en favor del discurso del desarrollo, como herramienta para privilegiar el sistema de desarrollo que se ha venido fortaleciendo y promulgando desde occidente; estos procesos llevan a contribuir con modos de vida y construcción de identidades alternativas que llevan a cuestionar estas ideas que propone el desarrollo y sus prácticas para conseguirlo. Así, el sumak kawsay es una propuesta alternativa para la creación de un desarrollo social, sostenible y equitativo. Es, entonces, el sumak kawsay un concepto que hace resistencia y oposición a las dinámicas capitalistas que reproducen dinámicas de poder colonizadas. A la luz de Eduardo Gudynas, el buen vivir puede entenderse desde tres miradas: las ideas, el discurso y las prácticas; el buen vivir se encuentra en una posición desde la cual proporciona cuestionamientos radicales a la idea de un desarro- 
llo generado desde el consumo acelerado; el discurso del buen vivir radica en su alejamiento de los discursos que celebran el crecimiento económico desde una mirada consumista; y el tercer plano, en el que este proyecto se basa, es el de las prácticas y actividades concretas que lleven a crear condiciones para el desarrollo del buen vivir. Por esto, se hace vital estudiar los conceptos del buen vivir, para así nutrir relaciones de convivencia sana con el otro y hacia el medio ambiente, a raíz de la armonización del ser (Gudynas, 2011).

En este orden de ideas, es importante partir del buen vivir como mecanismo de cuestionamiento dentro de un entorno en el que se da el crecimiento económico en el marco de un modelo de desarrollo generador de problemáticas, como la pobreza y la degradación del medio ambiente, "entendiendo el bienestar únicamente como un asunto de ingresos económicos o posesión material” (Gudynas, 2011, p. 232). Por lo tanto, el buen vivir surge como una filosofía de vida que se aparta de los discursos que celebran el consumo material como indicadores de bienestar, "en el sentido de convertirse en estrategias de acciones concretas, que no repitan las posturas convencionales que se critican y además sean viables" (Gudynas, 2011, p. 2), pensando en la calidad de vida por medio de alternativas que incluyan al ser humano y a la naturaleza. Así, el buen vivir debe proponer un conjunto de estrategias que superen limitaciones en proyectos específicos (hidroeléctrica o carretera) o reformas sectoriales (el caso de la privatización de la salud o educación). Entonces, es posible afirmar que el buen vivir es un cambio radical que interpreta y valora la naturaleza convirtiendo al ambiente en un sujeto de derechos, implicando transformaciones profundas en las ideas de desarrollo que van más allá de ajustes o correcciones dentro del modelo actual, pasando de "desarrollos alternativos" en los que se mantiene la misma racionalidad en la que se entiende el progreso como el uso de la naturaleza y las relaciones entre los humanos a "alternativas de desarrollo", en donde el buen vivir aparece como una gran corriente de reflexión que rompe con esquemas de antropocentrismo y se fun- 
damenta en principios como: igualdad, unidad, inclusión, dignidad, libertad, solidaridad, reciprocidad, respeto, equidad, bienestar, responsabilidad y justicia social.

Asimismo, se da una transición de antropocentrismo al biocentrismo, en donde el buen vivir cumple un papel fundamental, entendido no como un regreso al pasado, sino como una construcción de un futuro distinto proponiendo la incorporación de la naturaleza al interior de la historia, no como factor productivo ni como fuerza productiva, sino como parte inherente al ser social. Ahora bien, desde una perspectiva más autónoma, para Arturo Escobar, el proceso de la globalización es un proyecto fallido que utiliza como herramienta de expansión al desarrollo, y el "desarrollo es un proyecto tanto económico (capitalista-imperial) como cultural" (Escobar, 2010, p. 307).

En ese sentido el desarrollo, surge de una experiencia particular de modernidad europea que subordina las demás culturas y conocimientos transformándolos bajo principios occidentales, privilegiando el desarrollo económico bajo dinámicas de explotación de recursos naturales y lógicas del mercado que buscan la satisfacción material e individual, involucrando una serie de principios, los cuales Escobar establece de la siguiente manera: el individuo racional, no atado ni a un lugar ni a una comunidad; la separación de naturaleza y cultura; la economía separada de lo social y lo natural; la primacía del conocimiento experto por encima de todo otro saber. Entonces, se hace necesaria una política social y ambiental efectiva para el buen vivir, en donde se produzca un alejamiento por parte de los gobiernos progresistas de estas concepciones desarrollistas. "La mayoría de las políticas de los gobiernos están aún en contradicción con el buen vivir, pues continúan encarnando una visión modernista del desarrollo" (Escobar, 2010, p. 308). Como es el caso de Ecuador y Bolivia, que siguen atrapados en concepciones desarrollistas, es decir, se producen escenarios en los que se ha descentrado el dis- 
curso del desarrollo, creando espacios para la cultura, la naturaleza y aspectos no económicos, sin embargo, el modelo propuesto sigue siendo modernizante y dirigido por expertos. De esta forma, aunque vislumbra el posdesarrollo, no se adentra hacia él con paso firme.

Debido a esto se puede decir que los gobiernos progresistas no han logrado una reconversión significativa de los modelos de sociedad, economía, y vida. Entonces, se hace más que necesario una transformación que vaya más allá del Estado y las estructuras socioeconómicas; en otras palabras, esto involucra una transformación cultural y epistémica de modelos de mundo y modos de conocimiento. La descolonización epistémica debe acompañar la transformación de estructuras. "En los imaginarios, el posdesarrollo apunta a la creación de un espacio/tiempo colectivo, en el que el desarrollo cese de ser el principio central que organiza la vida económica y social" (Escobar, 2010, p. 311). Por lo tanto, se produce un fenómeno al que la ecologista y feminista Vandana Shiva define como 'monocultivos mentales'; esto es una extensión de pensamiento que sigue los mismos patrones, utilizando los mismos métodos genera la estandarización de la diversidad de pensamientos, la "diversidad se ve sustituida por los monocultivos, la red ecológica de la vida, por la bioingeniería, y su carácter sagrado, por sus posibilidades comerciales". (Vandana Shiva, 2012, p. 11).

En este orden de ideas, se produce una erosión de la diversidad humana y natural, partiendo de las problemáticas que han surgido del actual modelo de desarrollo y las consecuencias que han llevado a una crisis social, económica y ambiental, que de manera significativa exigen un cambio desde abajo. En ese mismo sentido, la economía se ha logrado establecer como un determinante del desarrollo, pensado desde occidente, y del progreso de un país, pensado desde un consumo acelerado, que utiliza los recursos naturales como fuente principal demateria prima. Según Astrid Agenjo, "la economía -como disciplina y ciencia moderna- se encuentra 
atada a una concepción histórica eurocéntrica, antropocéntrica y androcéntrica, a partir de las circunstancias de un espacio concreto (Occidente) y un sujeto particular (blanco, burgués, varón, adulto y heterosexual)" (2016, p. 6).

Esto nos permite introducir una propuesta muy fuerte dentro de los planteamientos del sumak kawsay, encaminada a establecer un desarrollo pensado en la equidad ambiental. Presenta el 'decrecimiento' como oportunidad de una estructura no solo económica, sino social, que permita un desarrollo integral y equitativo; un ejemplo de esto podría ser la justicia ambiental y el comercio justo, ambas estrategias encaminadas a repensar el desarrollo y generar un bienestar integral: "El Decrecimiento se concibe más bien como un slogan provocador, una herramienta para la movilización política y una propuesta para atreverse a salir del ideario económico dominante" (Pérez y Domínguez, 2015, p. 36). Sin embargo, a partir del evidenciado deterioro ambiental que han producido los modos de consumo acelerado y capitalista, estas posturas se presentan como una alternativa para demostrar la necesidad de un cambio estructural, tanto de los modos de producción como de las formas de consumo; si bien estos discursos han sido categorizadas como propuestas contrahegemónicas que han mantenido relación histórica con la producción capitalista, hoy más que nunca adquieren mayor relevancia al ser innegable la afectación del modelo neoliberal al norte económico, y adquieren un reconocimiento como solución a una crisis inminente (Pérez y Domínguez, 2015). Además de lograr una estructuración del modelo económico, es necesario establecer un nuevo modelo que le dé visibilidad a aquellas situaciones y categorías que el desarrollo occidental, lineal y neoliberal ha dejado de lado. Es necesario que este cambio estructural esté ligado no solo a la justicia ambiental y el comercio justo, sino también a la justicia de género:

Esta reelaboración es fundamental para transitar desde alternativas de Desarrollo, que hasta ahora han traído aparejadas desigualdades sociales 
y destrucción ecológica, hacia alternativas al Desarrollo a partir de las cuales se conciban las relaciones entre los seres humanos, y entre los seres humanos y la naturaleza, de forma igualitaria y sostenible (Pérez y Domínguez, 2015, p. 2).

Tal como lo ha manifestado Escobar, a raíz de los estudios de Juliana Flórez, establecer un nuevo modelo de desarrollo requiere de nuevos elementos. Muchos de estos elementos han sido establecidos por el sumak kawsay, pero se ha dejado de lado la importancia de los estudios de género, los cuales son indispensables para lograr un desarrollo integral:

En otras palabras, un enganchamiento con el feminismo y el ambientalismo sería fructífero en términos del pensamiento del lado no discursivo de la acción social (Flórez, 2003). Esto sería igualmente importante para teorizar futuras nociones que son centrales al grupo y a la teoría feminista, tales como epistemología, poder, identidad, subjetividad, agencia y vida cotidiana (Escobar, 2003, p. 71).

En este aspecto, los estudios de economía feminista se hacen cada vez más relevantes, puesto que se presentan mediante un discurso crítico, repensando la idea de desarrollo, que ha dejado de lado las posiciones de género, raza y sexo, establecida por un poder capitalista y occidental, dentro de la cual la economía es su principal herramienta. Profundizar en una mirada feminista y de género en torno a la construcción económica de lo que se entiende por desarrollo, que en últimas determina gran parte de los roles a desempeñar en la sociedad, permite delimitar "la función social del conocimiento y sus interrelaciones con el género, la subjetividad y el poder, con el propósito de contribuir a construir nuevas cartografías de saberes" (Del Moral 2012, párr. 1). Los estudios de economía feminista demuestran que

la construcción de económica hegemónica, que ha tomado como sujeto universal a los hombres y ha invisibilizado los problemas, las necesidades, 
las percepciones, los trabajos y los propios usos del tiempo de las mujeres, muy distintos a los masculinos (Pérez y Domínguez, 2015, p. 38).

De acuerdo con esto, Agenjo resume la importancia de este enfoque tras hacer un extenso recorrido teórico y establece que:

En suma, la finalidad de este enfoque sería establecer un punto de vista estratégico que permita desvelar el conflicto estructural entre la acumulación de capital y el sostenimiento de la vida, (Picchio 2001; Carrasco 2001; Pérez Orozco 2006, 2014), teniendo en cuenta el marco global en el que se lleva a cabo (Rai y Waylem 2014, Benería, Berik y Floro 2016) y abriendo nuevas preguntas en torno a la conexión desde la política económica neoliberal (el ajuste estructural, las políticas austericidas, los tratados de libre comercio...), pasando por los resultados en los indicadores macroeconómicos habituales, para llegar, al final, a cómo se establecen las condiciones de posibilidad de una vida digna para el conjunto de la población (2016, p. 7).

De tal forma las miradas feministas permiten ampliar el análisis de las dinámicas del desarrollo, su funcionamiento y establecimiento en el mundo moderno, basándose en categorías de raza, género y sexo. Permite, además, proponer nuevos discursos y estrategias viable para alcanzar un desarrollo sostenible:

Además de los asuntos del poder y la epistemología, las preocupaciones de la teoría feminista por la subjetividad e identidad son áreas cruciales de compromiso. [...] Para hablar sobre Latinoamérica: el hecho mismo de que el sexismo continúa siendo uno de los problemas más penetrantes y aparentemente intratables de las sociedades latinoamericanas sería razón suficiente para comprometerse con el feminismo (Escobar, 2003, p. 75).

Por otro lado, los estudios de decolonialidad abren el camino para emprender la búsqueda de un desarrollo alternativo y autónomo, que haga resistencia a las dinámicas de poder históricamente 
arraigadas a la visión de modernidad, permitiéndole no solo a los feminismos y estudios de género fortalecer sus argumentos, sino que le permite al sumak kawsay afianzarse en los ámbitos académicos e incursionar en el ejercicio práctico de proponer un desarrollo sostenible: "Más allá de las discusiones sobre la división del trabajo y de epistemología, esto ha tenido consecuencias visibles para el análisis de los procesos claves de la colonialidad, incluidas la construcción de la nación, la raza y las formaciones eurocéntrico-patriarcales" (Escobar, 2003, pp. 75-76. Cursivas añadidas).

\section{Género, decolonialidad y subjetividad}

Hemos establecido entonces que el sumak kawsay se ha destacado por enfrentar a las dinámicas de consumo salvaje, $\mathrm{y}$, por tanto, ejerce resistencia a todo aquello que supone un reflejo de la modernidad. Además, se ha caracterizado por sus esfuerzos en crear un desarrollo alternativo sostenible, pero hace uso de una filosofía particular enfocada en relaciones de convivencia sana con el otro, hacia el medio ambiente y consigo mismo; propone además un ejercicio de introspección del sujeto, por tanto, como establecimos previamente, no hay un solo buen vivir, sino múltiples buenos vivires; pero ‘hasta qué punto las relaciones entre el género, sexualidad y subjetividad puede ser comprendidas o enmarcadas como un sumak kawsay?

El género es un concepto que se ha ido transformando a lo largo de la historia, sin embargo, es un término novedoso, gracias a las acciones sociales y movimientos de grupos de diversidad sexual, mujeres y demás, quienes llevaron la discusión de lo que se entiende por género a la esfera privada y pública. El concepto puede ser analizado desde una cuestión de salud pública hasta una dimensión que comprende las relaciones socioculturales de una sociedad. Como lo discutimos, es un término que está sujeto a constantes transformaciones, siendo, al igual que el sumak kawsay, un concepto indefinido, amplio y general. 
Hay diversas posiciones frente al significado de género y sus implicaciones sociales; sin embargo, todas ellas concuerdan en que el género es un constructo social y cultural, generalmente asociado al sexo biológico. En ese sentido, el género es algo netamente subjetivo, un

(...) constructo social que pone de manifiesto las convenciones culturales, los roles y los comportamientos sociales que diferencian a las mujeres y los hombres y, por tanto, intenta diferenciar el sexo biológico de la forma en que la sociedad construye el «ser hombre» $\mathrm{O}$ «ser mujer» (Borrell, García-Calvente y Martí-Boscà, 2004, p. 2).

De tal forma, toda construcción social está atravesada por categorías específicas que determinan el funcionamiento de una sociedad, y el género no es una excepción. Preceptos como la cultura, la religión, el lenguaje, valores y demás hacen parte del funcionamiento de la vida en sociedad, por lo cual el género, una vez más es una

(...) construcción social, un conjunto de roles, características de personalidad, actitudes, valores y relaciones de poder e influencia que cada sociedad asigna a cada sexo (...) se basa en las relaciones y en ese proceso interactúa con el grupo étnico, la edad, la cultura y la posición socioeconómica (Winder y Torres, 2010, p. 7).

En un primer plano, el género es una actividad subjetiva, fruto de una introspección profunda, que da como resultado el desarrollo individual del género; entonces, es "una estructura social dinámica en la que hombres y mujeres son agentes activos en la construcción y reconstrucción de las normas dominantes de masculinidad y feminidad" (Courtenay, 2000). Sin embargo, se espera que el individuo adquiera comportamientos sociales dependiendo del sexo; es decir, la masculinidad y feminidad han sido construidas bajo los supuestos del sexo. Un hombre se determina según su sexo y de tal forma se espera que su género sea construido, sucede lo mismo con una mu- 
jer. De esta forma, vemos cómo el género y la identidad de género o identidad sexual se relacionan entre sí y mantienen una relación estrecha, por lo cual, el género y su amplia diversidad es en sí mismo una relación construida en sociedad. Simón de Beauvoir expresa en su libro El Segundo Sexo que la mujer no nace, sino que se hace, esto puede darnos mayor claridad para comprender el impacto del significado de género.

Gran parte de los estudios acerca del género presentan no solo una nueva visión sino una visión crítica respecto de las nociones convencionales acerca de lo masculino y lo femenino y que se han constituido como "legítimas e irrefutables basándose diferencias sexuales y sociales entre varones y mujeres (Bonder, 1999). Esta visión crítica ha permitido repensar las dinámicas jerárquicas y binarias que giran en torno al sexo y su relación con el género:

Un discurso restrictivo de género que insista en el binario del hombre y la mujer como la forma exclusiva para entender el campo de género performa una operación reguladora de poder que naturaliza el caso hegemónico y reduce la posibilidad de pensar en su alteración. (Butler, 2006, p. 71)

Como hemos establecido, el género, al ser un constructo social, es determinado por la sociedad y la cultura; puede ser visto como una estructura construida desde el patriarcado y la heteronormatividad, que determinan los comportamientos individuales desde el nacimiento, según sus estructuras de poder. En un primer plano podríamos establecer que el sumak kawsay, al ser un constructo social establecido desde una dinámica comunitaria, que permite el bienestar en las tres esferas de esta filosofía latinoamericana (consigo mismo, con los demás y con el ambiente que lo rodea), puede tener aspectos de convergencia con las identidades de género, las cuales, a su vez, son fruto de relaciones sociales cimentadas en la construcción, deconstrucción y dinámicas subjetivas constantes. Sin embargo, hemos establecido que es posible que el sumak kawsay como concepto 
socialmente construido no logre relacionarse con las identidades de género debido a que su proceso de construcción radica en gran medida de las costumbres y tradiciones ancestrales, míticas y sagradas, que usualmente son planteadas desde visiones heteropatriarcales, a lo que las identidades de género se oponen rotundamente. Surge entonces la pregunta de si ambos conceptos al ser socialmente construidos pueden estar encaminados a la reivindicación identitaria. Si realmente contienen bases y objetivos similares o incluso, en definitiva y la pregunta más importante es si pueden ser compatibles.

Esto supone un gran reto que a primera vista sería imposible de resolver, ya que requiere adentrarse a los más profundos elementos configurativos de ambos conceptos, esto bajo una gran complejidad al ser elementos de constantes cambios. Sin embargo, en función de establecer un intento de resolver nuestras preguntas, hemos decidido delimitar la investigación a una serie de elementos específicos: subjetividad y decolonialidad, esto al ser categorías presentes en ambos conceptos, cada uno por supuesto con su propia perspectiva, pero que nos permiten establecer una primera aproximación a la inquietud que deseamos resolver. Por tanto, los estudios de Luisa Posada nos muestran que

(...) la vida social está simbólica y materialmente dividida en dos géneros y que, entendiendo que estos son construidos, es de suyo cuestionar la estratificación política y económica, la división sexual del trabajo, el reparto de roles y, en definitiva, todas las categorías con las que se había manejado el pensamiento social y político hasta ese momento (Posada, 2015, p. 30).

Partimos, entonces, de que, "en su sentido más cabal, género alude a una relación de poder social que involucra tanto a las mujeres y lo femenino, como a los varones y lo masculino" (Bonder, 1999 , p. 2), y, por tanto, puede ser ordenador de la sociedad misma, en el sentido que determina las funciones, roles y comportamientos de los sujetos. Los aportes de Lucumí Moreno, Álvarez Maestre y 
García Muñoz, respecto del poder como genealogía del género, nos muestran que "los postulados actuales sobre género suponen que el proceso de construcción del género está cimentado en un sistema de poder cuyas simbolizaciones refuerzan constantemente la legitimación y naturalización de la identidad sexual heteronormativa" (2012, p. 92). Según esto, podríamos establecer que el poder se reproduce a sí mismo a través del individuo, que a su vez se desenvuelve en la sociedad desarrollando su propio poder, esto a través de elementos intangibles, como discursos, que lo legitiman: "los discursos reguladores que forman al sujeto del género son precisamente aquellos que requieren e inducen al sujeto en cuestión” (Butler, 2006, p. 68).

Esto nos lleva a preguntarnos cómo funciona el poder y cómo éste incide en la construcción del sujeto:

El poder se sostiene en la medida en que los sujetos se movilizan dentro de él, la fuerza y el engaño a veces no son necesarios; el hecho de que el poder forme saberes, organice líneas de pensamiento, movilice al deseo, produzca beneficios para unos o para otros, que sea un proceso de disciplinamiento y no de represión, facilita que los actores sociales se definan dentro de una realidad que determina sus acciones y sea fortalecida con el discurso (Moreno, Maestre y Muñoz, 2012, p. 94).

De esta forma, como lo hemos establecido anteriormente, el sumak kawsay hace resistencia a patrones de poder, especialmente a aquellos establecidos por los efectos de la globalización y, por ende, a la Modernidad. Respecto a eso, Aníbal Quijano, investigador del Consejo Latinoamericano de Ciencias Sociales (CLACSO), establece que dicha globalización se ha establecido desde la constitución de América Latina y un capitalismo colonial / moderno y eurocentrado dentro de los patrones de poder mundial (2014).

(...) no hay modernidad sin colonialidad y, a su vez, la colonialidad supone a la modernidad; de ahí que se afirme que la relación entre moderni- 
dad y colonialidad es de co-constitución: no puede existir una sin la otra (Restrepo y Rojas, 2010, p. 17).

Estos patrones de poder colonizado, a la luz de Quijano, fueron establecidos en un principio según criterios de raza que, posteriormente, fueron replicados por medio del capital a todos los segmentos sociales y políticos. Si bien sostiene que esos patrones de poder se establecen según criterios de raza, este artículo propone que esos patrones de poder colonizado pueden estar también cimentados en criterios de género y sexo.

Se hace indispensable en la medida que la identidad de género se ha presentado como un concepto estático, binario y que ha sido legitimado por un lenguaje cientificista. Establecer estudios y herramientas de decolonialidad permiten desmontar discursos establecidos toda vez que la colonialidad

(...) es un fenómeno histórico mucho más complejo que se extiende hasta nuestro presente y se refiere a un patrón de poder que opera a través de la naturalización de jerarquías territoriales, raciales, culturales y epistémicas, posibilitando la re-producción de relaciones de dominación. (Restrepo y Rojas, 2010, p. 13)

Es común al estudiar la decolonialidad del poder encontrar estudios profundos sobre la colonización de culturas e identidades, usualmente relacionadas a los mismos conceptos de raza y etnia que Quijano propone, e insisten en luchar por una decolonialidad completa de estos conceptos en función de lograr una reivindicación autónoma. Estos estudios proponen establecer los cimientos ancestrales y deteriorados por los conceptos occidentales de la modernidad, algo muy relevante para el sumak kawsay: "La explotación y dominación global actual, la distribución del poder y la riqueza mundial, se establece siguiendo aún esa distinción entre las 'razas', 'etnias' o 'naciones' de las poblaciones colonizadas y la de los colonizadores”. 
(Restrepo y Rojas, 2010, p. 94). La colonialidad no solo se ve representada en las dinámicas de poder, sino que hace uso de estas para llegar a los elementos culturales, sociales, económicos, políticos e incluso al ámbito privado. Por tanto, las identidades de género y el sumak kawsay no solo deben luchar por la decolonialidad del poder, sino también por la decolonialidad del Ser:

Como punto de partida podemos argumentar que la colonialidad del ser refiere a los efectos de la colonialidad en la experiencia vivida de los subalternos coloniales, pero también en los sectores dominantes. (...) Así, podemos afirmar que la inferiorización del subalternizado colonial, que en su punto extremo aparece como deshumanización, es una de las características de la colonialidad del ser (Restrepo y Rojas, 2010, p. 158).

La colonialidad del ser no es sino un efecto de la colonialidad del poder. La modernidad no solo logró establecer los parámetros “ideales” de la política, la economía, la cultura y, por ende, la sociedad, sino que intervino en la corporalidad de las personas, delimitando un ser ideal y un ser imperfecto. De tal forma la colonialidad del ser se adentra en la sexualidad y, por tanto, diseña lo que es aceptable e incluso moral para la sociedad moderna. Al igual que su antecesora (la colonialidad del poder), la colonialidad del ser presenta una separación entre lo moderno y lo no-moderno, entre lo correcto y lo incorrecto, pero en los ámbitos privado del sujeto; plantea una forma suprema de vida y por tanto incluye todos los aspectos del ser: sus creencias, su sexualidad entre otros:

La reducción del género a lo privado, al control sobre el sexo y sus recursos y productos es una cuestión ideológica presentada ideológicamente como biológica, parte de la producción cognitiva de la modernidad que ha conceptualizado la raza como «engenerizada» y al género como racializado de maneras particularmente diferenciadas entre los europeos-as/blancos-as y las gentes colonizadas/no-blancas. La raza no es ni más mítica ni más ficticia que el género -ambos son ficciones poderosas (Lugones, 2008, p. 93-94). 
Ahora, con relación a lo establecido respecto a la construcción del género, y para hacer un poco evidente su relación con la colonialidad del ser, se hacen relevantes nuevamente los estudios de Gloria Bonder, quien manifiesta que históricamente la sociedad

(...) presuponía la existencia de una identidad personal o de un yo delimitado originario, que, a través del proceso de socialización, primero en la familia, y luego en los distintos ámbitos sociales, adquiría las capacidades, motivaciones y prescripciones propias de su identidad genérica adaptándose a las expectativas y mandatos culturales. En otros términos, afirmaba que la sociedad tiene un libreto que debe ser aprendido y que ese aprendizaje garantiza la reproducción de un orden de género sin fisuras. (Bonder, 1999, p. 1).

O en palabras de Judith Butler, cada sujeto está condicionado por la matriz heterosexual que determina no solo su sexualidad, sino su género y puede determinar incluso su corporalidad. Butler evidencia en esto un sometimiento del sujeto, en el cual se convierte en garante de su propia resistencia y oposición al poder que se le ha instaurado.

El género es algo en sí mismo fluido y es a la larga una construcción personal. Las identidades de género y los colectivos de libertad sexual evidencian

(...) la necesidad de la "implosión" de la categoría de género tal como ha sido utilizada hasta ahora, para hacer emerger las múltiples posiciones de género que se derivan de un proceso de subjetivación atravesado por relaciones de poder asimétricas, relativas a la etnicidad, raza, clase, edad, orientación sexual, entre otras (Bonder, 1999, p. 4).

Entonces, entendemos la subjetividad como un acto subversivo. En situaciones en las cuales el género se ha reducido a un binarismo, la subjetividad y las identidades de género surgen como un acto 
revolucionario de reivindicación de las corporalidades transgredidas por la heteronormatividad patriarcal y por el reduccionismo masculino/femenino:

(...) la subjetividad se construye en y a través de un conjunto de relaciones con las condiciones materiales y simbólicas mediadas por el lenguaje, lo cual requiere aceptar, entre otros aspectos, que toda relación social, incluida la de género, clase o raza, conlleva un componente imaginario (Bonder, 1999, p. 4).

Por tanto, urge la necesidad de plantear estos mismos conceptos de descolonización para las identidades de género, que, si bien no están determinadas del todo por conceptos occidentales de raza y capital, sí lo están por conceptos de heteronormatividad, patriarcado y estructuras de poder colonizadas: todo control del sexo, la subjetividad, la autoridad, y el trabajo, están expresados en conexión con la colonialidad (Lugones, 2008, p. 79).

En situaciones en las cuales los cuerpos han sido restringidos, la sexualidad ha sido reducida al binarismo absoluto, donde el ser heterosexual patriarcal triunfa sobre la diversidad, el Sumak Kawsay y su propuesta de los buenos vivires se presenta como una alternativa viable para la construcción de las subjetividades y el desmonte de estructuras de poder modernas; sin embargo, la pregunta de si es posible que las identidades de género y los feminismos sean compatibles al sumak kawsay sigue vigente. En ese sentido, podemos observar el caso concreto del sumak kawsay como un proceso aparentemente exitoso en la descolonización de las culturas e identidades, sobre todo indígenas, que no se enmarcan en los conceptos occidentales y globalizados. No obstante, como nos demuestran Soledad Varea y Sofía Zaragocin:

En el caso del Ecuador, el país se ha caracterizado como mega-diverso en torno a la diversidad cultural y su naturaleza, pero en cuanto a la sexua- 
lidad y orden de género impulsado desde el Buen Vivir, la diversidad se limita y se ordena de acuerdo a parámetros definidos por una heteronormatividad uninacional. (2017, p. 8)

El Sumak Kawsay ha logrado un impacto no solo en su continente, sino que ha logrado atraer la mirada mundial con su discurso descolonizante del poder en diferentes aspectos; sin embargo, "su relación con el feminismo activista, político o académico no ha sido un pilar para la construcción conceptual del Buen Vivir como sí lo han sido otros temas tales como la naturaleza, el desarrollo y la interculturalidad” (2017, p. 17). A pesar de que los estudios e identidades de género y el sumak kawsay recogen elementos de decolonización, no comparten visiones similares; por su parte, las identidades de género desean establecer una decolonización de los roles y comportamientos asociados al género, esto en sí mismo de su raíz de modernidad occidentalizada, desde la cual los roles de género fueron creados; $\mathrm{y}$, por otro lado, el sumak kawsay desea la decolonización de las culturas, la producción científica de conocimiento y, por supuesto, de los modelos económicos y políticos de la modernidad occidentalizada. Pareciera entonces que es este rasgo común el que le permitiría al sumak kawsay y a las identidades de género ser compatibles; que estas dos dimensiones ideológicas trabajen de manera mancomunada en su lucha por la decolonización de cada aspecto social e ideológico les permitiría tener un mayor impacto.

\section{Buen vivir, decolonialidad y feminismo}

Cuando la filosofía del buen vivir cobra importancia en gobiernos latinoamericanos, como el de Bolivia y Ecuador, se empiezan a generar espacios que dieron continuación al debate sobre el orden del género dentro de las cosmovisiones indígenas, dando paso a nociones de igualdad de género, la despatriarcalización y la descolonización, dejando como consecuencia un Plan Nacional de Desarrollo con un enfoque de igualdad de género en Ecuador y el Plan Quin- 
quenal de las mujeres para el Vivir Bien en Bolivia; impulsando, por medio del buen vivir, una sexualidad y un orden de género diversos, que se limitan y ordenan de acuerdo con los parámetros definidos por una heteronormatividad uninacional y patriarcal, como mencionamos anteriormente.

Es así como se generan escenarios en los que se promueven procesos de hibridación entre el buen vivir y el feminismo, relacionándose a través de las visiones y los estudios de los feminismos decoloniales y comunitarios que se desarrollan bajo la dinámica del sumak kawsay. En esto se produce una tendencia que promueve una ecología de saberes feministas que generan una ruptura con la modernidad capitalista. Estos saberes se han originado por medio de la diversidad de definiciones del buen vivir, logrando una descolonización del conocimiento, que lleva a un cuestionamiento sobre los fundamentos de las epistemologías de lo moderno, lo occidental y hegemónico. Asimismo, se repiensa el patriarcado en relación con la Pachamama y el territorio desde una perspectiva del feminismo comunitario. Por lo tanto, es posible decir que se da un cuestionamiento por parte del sumak kawasay a los paradigmas coloniales en ámbitos políticos y económicos, que es evidenciado también por enfoques como feminismos decoloniales, indígenas y comunitarios. "El feminismo decolonial y el Buen Vivir enfrentan, conceptualmente hablando, el desafío de crear una epistemología decolonial a partir de los espacios imaginarios de la poscolonialidad y la decolonialidad" (Zaragocin, 2017, p. 18). De cualquier modo, la importancia recae no solo en juntar dos culturas, sino en crear un nuevo espacio que haga posible una tercera vía que no se encuentra ni en el centro ni en la periferia, por el contrario, sea una hibridación que permita la diferenciación.

Sin embargo, es importante tener en cuenta que la hibridación entre el feminismo decolonial y el buen vivir no significa una propuesta entre la modernidad y lo no moderno, por el contrario, son una serie de procesos comunes y parejos que buscan rescatar un 
espacio en el que se logre la representatividad de lo subalterno, es decir, se trata de un proceso conjunto contra la violencia epistémica sobre la que ha recalcado Spivak (1994).

El feminismo decolonial representa el intento por articular varias tradiciones críticas y alternas a la modernidad occidental y, sobre todo, del pensamiento radical feminista de Nuestramérica. En este sentido, se reclama heredero, por un lado, del feminismo negro, de color y tercermundista en los Estados Unidos, con sus aportes sobre la manera en que se articula la opresión de clase, raza, género y sexualidad y la necesidad de reproducir una epistemología propia que parte de reconocer esta inseparabilidad de la opresión. Por otro lado, recupera el legado de las mujeres y feministas afrodescendientes e indígenas que desde Abya Yala han planteado el problema de su invisibilidad dentro de los movimientos sociales y dentro del propio feminismo (Espinosa, 2014, p. 32).

Entonces, se produce un direccionamiento del feminismo decolonial y el buen vivir, en tanto se busca analizar fenómenos sociales como la colonialidad y el racismo como epistemologías de la modernidad. Desde este punto, se puede señalar que

(...) la construcción de nuevos marcos epistemológicos que incorporan y negocian conocimientos occidentales y conocimientos no-occidentales, indígenas pero también negros (y sus bases teóricas y vivenciales, pasados, pero también presentes), siempre manteniendo como fundamental la necesidad de enfrentar la colonialidad del poder a lo cual estos conocimientos han sido sometidos (Walsh, 2004, p. 3).

Es decir, se ha generado una sistematización de saberes en torno a los seres humanos y su relación con la naturaleza. En este sentido, podemos observar que el buen vivir al ser parte de una colectividad amplia y plural, tiene una correspondencia con los feminismos colectivos, en tanto se origina una pluralización de las voces y los lugares desde los cuales se generan críticas a la colonialidad y moder- 
nidad, relacionándose de manera coherente y extendiéndose a partir de nuevas reflexiones que no tienen una autoría individual, sino colectiva. Asimismo, es de rescatar que el feminismo decolonial recoge las críticas de la corriente feminista autónoma latinoamericana; en este sentido, éste es clave para cuestionar el discurso de igualdad de género. Entonces, la relación híbrida entre feminismo decolonial y buen vivir tiene mayor y estrecha relación en torno a la crítica a la igualdad identificada con procesos de reconocimiento cultural. Por ende, podemos establecer que la efusión entre igualdad de género y desarrollo configura un escenario desde el cual se puede abarcar una crítica, que tiene como eje dos temas centrales que se han estado desenvolviendo en un marco de luchas políticas de los pueblos indígenas con el fin de garantizar sus derechos y en contra de políticas desarrollistas que en nombre del 'progreso' disculpan (justifican) el despojo de las comunidades y de sus recursos naturales.

A causa de esto, se han desarrollado una serie de reformas en los países latinoamericanos con el fin de lograr un reconocimiento del carácter multicultural de la nación, de los derechos colectivos de los pueblos indígenas, el reconocimiento a sus sistemas normativos y formas de autogobierno y el derecho a utilizar y preservar sus propios idiomas indígenas.

No obstante, los compromisos contraídos en estas nuevas legislaciones, en los últimos años, estamos siendo testigos de un retroceso en el reconocimiento de los derechos políticos y territoriales de los pueblos indígenas y de una embestida de violencia y despojo contra sus territorios y recursos naturales (Castillo, 2005, p. 26).

En sentido concreto, es visible una apropiación por parte de los Estados latinoamericanos de estos conceptos; sin embargo, son estos los que están dotándolos de retóricas gubernamentales para justificar un nuevo desarrollismo "posneoliberal". En otras palabras, se da una construcción de la diversidad cultural y de derechos, pese a esto 
(...) se imponen megaproyectos extractivos mineros, petroleros, forestales; de energía e infraestructura como represas, proyectos eólicos y carreteras; y promoviendo la siembra de monocultivos y transgénicos en los territorios de los pueblos indígenas, sin consulta ni consentimiento previo, libre e informado (Castillo, 2015, p. 27).

Lo anterior crea un retroceso respecto a los derechos de la tierra y la consulta previa, contaminando ríos y bosques, con la excusa de resguardar los intereses nacionales, lo que justifica dinámicas que violentan y desprotegen los pueblos originarios (aborígenes).

Actualmente en América Latina es muy similar, por su violencia y expansionismo, a la etapa de acumulación originaria, en la que las potencias coloniales se valieron del despojo, la privatización de la tierra, la expulsión por la fuerza de las poblaciones campesinas subyugadas, el despojo de sus recursos naturales, así como de la mercantilización de las formas alternativas de producción y consumo de los pueblos colonizados (Harvey, 2003 , p. 30).

En vista de la ampliación de los territorios de reinversión, las tierras de los pueblos indígenas están siendo afectadas por el despojo y la violencia del "desarrollismo". Sin embargo, se ha evidenciado cómo en distintas regiones de países Latinoamericanos ha resurgido la participación de mujeres indígenas que, por medio de movimientos de resistencia, permanentemente luchan contra el despojo y la mercantilización de sus tierras y recursos naturales; reivindicando sus valores ancestrales como un referente para la defensa de la tierra y el territorio y para confrontar las múltiples violencias que afectan sus vidas.

Un ejemplo de ello es el de la red de mujeres del Chimborazo (REDMUJCH) que ha sido analizada por la activista e intelectual kichwa Cristina Cucuri, quien a partir de su experiencia expresa la lucha de esta red de mujeres por integrar sus perspectivas del buen vi- 
vir en la Constitución ecuatoriana del 2008, mediante el documento "Nosotras en la Constituyente". El citado documento fue elaborado por doce lideresas indígenas parroquiales, cantonales y provinciales que, basándose en las propuestas planteadas en los diferentes talleres en comunidades de la región del Chimborazo, plantearon una agenda que incluía el concepto del "Buen Vivir" como epistemología crítica ante la violencia de género:

En esta propuesta partían de pensar el "Buen Vivir como la armonía y la paz con la naturaleza y la paz, con nosotras mismas y nuestros antepasados; como un camino hacia los derechos de las mujeres, por eso fuimos a construir la Constitución. Logramos mucho: los grupos prioritarios, los derechos de la naturaleza y el Estado Intercultural y Pluricultural” (Cucuri, 2013, p. 55).

Debido a las luchas de la REDMUJCH y de otras mujeres y hombres aliados, la Constitución ecuatoriana del 2008 en su artículo 57, numeral 10, establece "Crear, desarrollar, aplicar y practicar su derecho propio o consuetudinario, que no podrá vulnerar derechos constitucionales, en particular de las mujeres, niñas, niños y adolescentes".

Del mismo modo, se conoce un movimiento en defensa de los bosques liderado por mujeres que se inició en el Himalaya (Chipko "abrazo"). "Para las mujeres rurales de la India, los bosques proveían todo lo necesario para el sustento: agua, comida, combustible, forraje y medicinas" (Shiva, 1997, p. 127). La principal causa de su propuesta es el desprendimiento de la tierra en causa de la forestación, sin dejar de lado que las consecuencias de la actividad de la industria maderera eran amplias y desastrosas: los arroyos estaban desapareciendo y las inundaciones y las sequías se agravaba, lo que repercutió en una mayor escasez de combustible y de alimento para el ganado. Precisamente, la tala de árboles ha sido uno de los mayores negocios de la India desde que las políticas coloniales convirtieron los montes comunales 
en materia prima para la industria de madera británica: "Han sido las propias mujeres indígenas, desde perspectivas no esencialistas de la identidad indígena, las que han dado pistas de cómo re-pensar el género desde la cultura y la cultura desde el género" (Castillo, 2015, p. 33). Entonces, en un primer plano podríamos establecer que hablar de productividad y desarrollo significa también hablar de pobreza y desigualdad, práctica que fragmenta, reduce y viola la integridad del bumano con la naturaleza, sin dejar de lado las nuevas formas que ha adoptado la violencia contra las mujeres, teniendo en cuenta que las estructuras patriarcales tradicionales se han ido hibridando con las estructuras del patriarcado capitalista; entonces:

Hemos de analizar las relaciones entre la violencia de los sistemas económicos injustos y no sostenibles y la frecuencia y crueldad crecientes de la violencia contra las mujeres. Hemos de comprender cómo se intensifica la violencia contra las mujeres debido a la fusión de las estructuras del patriarcado tradicional con las estructuras emergentes del patriarcado capitalista (Shiva, 2011, p. 18).

Los supuestos en los cuales se da este modelo de desarrollo patriarcal son evidentes, la agricultura orgánica significa pobreza, la naturaleza es improductiva, las mujeres, pueblos tribales y sociedades campesinas son igualmente improductivas. Es más que evidente que se está produciendo un mal desarrollo en pensamiento y en acción, que se ha legitimado por medio de la propuesta de un proyecto cultural tendencioso, destruyendo los estilos de vida sostenibles, creando una pobreza que es resultado del desposeimiento y privación bajo una dinámica en la que las sociedades industrializadas requieren mayor cantidad de energía y recursos para funcionar, excluyendo a un gran número de personas con poco poder adquisitivo, además de restar recursos para su supervivencia. "La mentalidad que ha generado la crisis no puede ofrecer soluciones" (Shiva, 1995, p. 150), afirma insistentemente Vandana Shiva, que en el enlace entre ciencia moderna y desarrollo capitalista radica la causas de la crisis 
ecosocial, estableciendo que hay un estrecho vínculo entre la dominación de la naturaleza, la subordinación de las mujeres y la opresión de los pueblos no occidentales. El vínculo se juega en el manejo de una lógica de la dominación, fundamentada en la dicotomía jerarquizada actividad/pasividad, que inferioriza y subordina mediante el recurso, de doble dirección, de naturalización y feminización:

Ambas son consideradas el "otro", el no yo pasivo. La actividad, la productividad y la creatividad que van asociadas al principio femenino, han sido expropiadas como cualidades de la naturaleza y la mujer y transformadas en cualidades exclusivas del hombre. (...) De creadoras y sustentadoras de la vida, la naturaleza y la mujer están reducidas a ser "recursos" en el modelo de mal desarrollo, fragmentado y contrario a la vida (Shiva, 1995 , p. 35).

Por esta razón, en la actualidad muchas personas toman conciencia de la situación del medio ambiente, y ecologistas de todo el mundo se vuelven hacia las creencias de los pueblos indígenas de América con el fin de vivir en armonía con la naturaleza. Algunos discursos potencializan a la evidencia la relación de las dinámicas capitalistas y de consumo acelerado con el detrimento del medio ambiente. Sin embargo, no solo el capitalismo ha sido comprendido como medio que sostiene el detrimento del medio ambiente. Algunas feministas consideran que es importante estudiar cómo el capitalismo se ha mantenido como sistema por tanto tiempo a pesar de las consecuencias evidentes que ha presentado. De tal forma, consideran que el patriarcado soporta el capitalismo, por lo cual, para lograr una crítica integral hacia el capitalismo es necesario criticar el patriarcado y desmontarlo.

Algunas teorías establecen que

(...) el género y las relaciones sexuales constituyen un sistema autónomo que se combina con el capitalismo y da nueva forma a las relaciones de 
clase, sin dejar de ser al mismo tiempo, modificado por capitalismo en un proceso de interacción recíproca. (Arruza, 2014, p. 2).

Esta teoría comprende el género y la raza como categorías de explotación y, por tanto, de opresión, en tanto la sociedad se sectoriza en función de estas, afectando las relaciones económicas:

En general, dentro de esta hipótesis, las relaciones de clase están caracterizadas esencialmente en términos estrictamente económicos: es la interacción con el patriarcado y el sistema de dominación racial que les da un carácter que va más allá de la mera explotación económica. Una variante alternativa de esta hipótesis, sin embargo, es la que ve en las relaciones de género un sistema de relaciones culturales e ideológicas producto de los modos de producción precapitalistas y formaciones sociales independientes del capitalismo, que interviene en las relaciones capitalistas, dándoles una dimensión de género (Arruza, 2014, p. 2).

Esto nos muestra que las relaciones de opresión y explotación se establecieron en situaciones precapitalista, en donde se ejercía una división sexual del trabajo, por supuesto, patriarcal.

El capitalismo en sí es indiferente a las relaciones de género y podría funcionar sin la opresión de género hasta tal punto que el capitalismo ha disuelto el patriarcado en los países capitalistas avanzados y ha reestructurado radicalmente las relaciones familiares. (Arruza, 2014, p. 2).

Por tanto, el capitalismo se presenta como instrumento para el patriarcado para fortalecer la rígida división sexual del trabajo y ahondar en la desigualdad del género.

Esto podría hacer pensar que el capitalismo es un sistema netamente económico; sin embargo, es a su vez "un complejo y detallado orden social, que contiene en su seno las relaciones de explotación, dominación y alienación” (Arruza, 2014, p. 2). Así, los feminismos 
que critican al capitalismo tratan de resolver cómo el capitalismo ha logrado reproducir las dinámicas de opresión y explotación en función del género que el patriarcado estableció. "El capitalismo no tiene una disposición estructural que cree desigualdades de género, es más, incluso tiene una tendencia natural a poner en tela de juicio tales diferencias y diluir las identidades raciales y de género". (Arruza, 2014, p. 10). De tal forma, para comprender las relaciones del patriarcado con el capitalismo, las feministas de esta corriente proponen aplicar un método de estudio histórico. Comprender que las relaciones patriarcado y capital se desarrollaron de forma histórica, con las particularidades de cada cultura. Se debe comprenden que

(...) la opresión de género y la opresión racial no corresponden a dos sistemas autónomos que tienen sus propias causas particulares: se han convertido en una parte integral de la sociedad capitalista a través de un largo proceso histórico que ha disuelto anteriores formas de vida social (Arruza, 2014, p. 16).

De tal forma, los feminismos decoloniales, ambientalistas y anticapitalistas (catalogados también como marxistas), no solo hacen una crítica a la modernidad occidentalizada, sino que con ello logran fortalecer los discursos respecto de la necesidad de establecer un nuevo modelo económico y social que no afecte los recursos naturales, ni prolongue acciones patriarcales. Pareciera ser este un punto de convergencia con el Sumak Kawsay.

\section{Consideraciones finales}

Hemos establecido que el sumak kawsay es una corriente filosófica que nace a partir de las comunidades indígenas y su impacto político y social en los países de Bolivia y Ecuador. Es una filosofía de vida con antecedentes ancestrales, que, entre tantas cosas, pretende lograr una reivindicación de las identidades, cultura y cosmovisiones de las comunidades indígenas que fueron invisibilizadas por la mo- 
dernidad occidental. De igual forma, el sumak kawsay busca hacer resistencia a los discursos de consumo acelerado, que, bajo el capitalismo salvaje, representa un detrimento de los recursos naturales.

El sumak kawsay a su vez se ha caracterizado por ser una corriente filosófica constantemente en construcción, enfocada a lograr un cambio social, encaminado a la erradicación del consumo acelerado y el establecimiento de la naturaleza en la vida del ser social. Dentro de esos esfuerzos ha logrado integrar cambios en su filosofía. Ha integrado las discusiones sobre identidad ancestral e indígena, y las discusiones sobre los roles de género, sobre todo en las comunidades indígenas:

En resumen, el discurso del "buen vivir" es una construcción social que da paso al diseño y gestión de un modo de vida que cuestiona el discurso blanco-mestizo sobre el cual se habían concebido y practicado proyectos de modernización en el Ecuador. En este sentido, el "sumak kawsay" es un ejercicio político que transforma el discurso del mestizaje (Cortez, 2011, p. 4).

Si bien el sumak kawsay resalta la necesidad de retomar sabores ancestrales que la globalización y la modernidad han desechado, esto se basa en la tradición histórica; es decir, el sumak kawsay se enfoca, entre otras cosas, a rescatar las identidades y culturas ancestrales que han sido sentenciadas al olvido: "Buen Vivir permite el reforzamiento de identidades, y para muchas culturas se pone en juego sus esencias, y no sus márgenes” (Varea y Zaragocin, 2017, p. 19). Podríamos plantear que el sumak kawsay desea una reivindicación de las culturas y las identidades con un recorrido histórico y ancestral que fueron relegadas por la modernidad, es por tanto que la teoría de la decolonialidad toma fuerza, sobre todo en el ámbito identitario.

El sumak kawsay busca reivindicar las identidades y culturas, principalmente indígenas, que fueron colonizadas. Estas identida- 
des poseen una gran importancia histórica, en tanto buscan rescatar los saberes ancestrales y van en contra del cientificismo occidental del conocimiento autónomo, rescatando la historia y cultura propia de los pueblos. Por el contrario, las identidades de género buscan romper con el binarismo histórico al que se han reducido las identidades de las diversidades sexuales. Las identidades de género desean establecer una decolonización de los roles y comportamientos asociados al género, esto en sí mismo de su raíz de modernidad occidentalizada, desde la cual los roles de género fueron creados.

De tal forma, este es un obstáculo para el matrimonio entre el sumak kawsay y las identidades de género. Si bien el primero establece múltiples buenos vivires, estos hacen referencia a los sabores ancestrales y culturas de las diversas comunidades indígenas, ya que es una filosofía de vida cuyo origen radica en las comunidades aborígenes, por lo cual la ancestralidad, la ritualidad y la historia son elementos de difícil convergencia, especialmente con las identidades de género, las cuales van en contra de lo anterior. Ahora, si bien el sumak kawsay ha logrado concesiones en temas de género, no presenta convergencias directas con las identidades de género y de diversidad sexual, $y$, aunque ambos podrían verse involucrados en la teoría de la decolonialidad, cada uno busca un objetivo diferente. Aun así, las convergencias del sumak kawsay en temas de género, vemos que ha logrado avances respecto a la equidad de género, ejemplo de esto son los movimientos feministas e indígenas que lograron los cambios legales en Ecuador y Bolivia que discutimos anteriormente:

Sus propuestas se formulan desde la "equidad de género" como planteamiento central. A partir de aquí se esbozan lineamientos y propuestas concretas respecto a un mayor reconocimiento legal y constitucional de las demandas de las mujeres, de un "comercio justo", de una "sexualidad plena", de una "educación incluyente" y de una "economía comprometida (Cortez, 2011, p. 17). 
Si bien establece la equidad de género y ha trabajado por la valoración del trabajo del cuidado, sobre todo de la mujer indígena, entiende el género desde una visión binaria entre masculino y femenino, por tanto, esta equidad la plantea más como una especie de igualdad entre sexos. Entonces, deja de lado la diversidad sexual y sigue planteando el género como un dualismo heterosexual, apartando no solo las orientaciones sexuales (homosexualidad, bisexualidad, etc.), sino que no logra la misma reivindicación social con las identidades de género como con las identidades aborígenes o ancestrales. Es importante establecer que el sumak kawsay busca la reivindicación de las identidades, pero no todas las identidades pueden hacer parte de esta filosofía de vida.

Sin embargo, logramos establecer que el buen vivir tiene similitudes y discrepancias con respecto a los feminismos, es decir, estos dos se han caracterizado por hacer resistencia a procesos de colonización, asimismo, han compartido escenarios de luchas sociales en función del medio ambiente. No obstante, se ha evidenciado la manera en la cual han sido relegados, no solo los enfoques de género, sino una total invisibilización a los movimientos feministas por parte de los discursos dominantes del buen vivir. Aunque de la misma forma se ha demostrado que el buen vivir está en la constante búsqueda de espacios fuera de la modernidad, se ha mantenido como impedimento para la posibilidad de generar innovación con relación a las identidades de género. Es entonces cuando se debe plantear la necesidad de adoptar un eje de convergencia que permita una transformación de las diferentes teorías para su adaptación.

Es posible que el sumak kawsay y las identidades de género no presenten tantas convergencias; sin embargo, con los feminismos, las similitudes son mayores. Por tanto, debemos ser cuidadosos con esta unión. No todos los feminismos son iguales; son los feminismos decoloniales, comunitarios, ambientales y marxistas los que pueden lograr una confluencia con el sumak kawsay. 
Vemos entonces que, dentro de los feminismos comunitarios, los decoloniales y el buen vivir, se puede lograr una especie de hibridación, es decir, lograr un espacio alternativo en el que esta interrelación produzca como resultado una epistemología intercultural dentro de espacios poscoloniales. De igual forma, se puede rescatar que dentro del buen vivir se genera una pluralidad en torno a conocimientos colectivos e históricos que suponen una constante hibridación, ya que se hace referencia a los buenos vivires. Por esta razón, se propone que por medio de políticas públicas feministas se visibilice lo que se puede denominar como una utopía del buen vivir desde las diferentes posturas del feminismo. En consecuencia, debemos asumir que el sumak kawsay y su relación con los feminismos se trata de un proceso de constante construcción, de hibridación, basado en conceptualizaciones que no tienen autoría individual, sino colectiva y que surgen en este espacio poscolonial y decolonial.

\section{Referencias}

Arango, L. G., Castellanos, G., Fuller, N., Kaufman, M., Lamas, M., León, M., Montecino, S., Muñoz, S., Sáenz, J., Santos, L., Segura, N., \& Viveros, M. (1995). GÉNERO E IDENTIDAD Ensayos sobre lo femenino y lo masculino.

Arruza, C. (2016). Reflexiones degeneradas: Patriarcado y capitalismo. SinPermiso, 1-16

Bonder, G. (1998). Género Y Subjetividad.

Butler, J. (2006). Deshacer el género. Barcelona: Ed. Paidós.

Cortez, D. (2008). La construcción social del "Buen Vivir" (Sumak Kawsay) en Ecuador Genealogía del diseño y gestión política de la vida.

Escobar, A. (2003). Mundos y conocimiento de otro modo. Tabula Rasa, (1), 51-86.

Gudynas, E. (2011a). Buen vivir: Germinando alternativas al desarrollo. América Latina en Movimiento.

Gudynas, E. (2011b). Tensiones, contradicciones y oportunidades de la dimensión ambiental del Buen Vivir. En I. Farah y L. Vasapollo (coords.), Vivir Bien: ¿Paradigma 
No Capitalista? (pp. 231-246). Universidad Mayor de San Andrés (CIDES-UMSA) y Departamento de Economía de la Universidad de Roma.

Lucumí, E., Álvarez, A., \& García, C. (2012). El poder como genealogía de la identidad de género. Revista Colombiana de Ciencias Sociales, 3(1), 91-103.

Lugones, M. (2008). Colonialidad y género. Tabula Rasa, (9), 73-101.

Mies, M. y Shiva, V. (1997). Ecofeminismo: teoría, crítica y perspectivas. Ícara.

Pérez, L. y Domínguez, M. (2015). Una revisión feminista del Decrecimiento y el Buen Vivir. Contribuciones para la sostenibilidad de la vida humana y no humana. Revista de Economía Crítica, (19), 34-57.

Posada Kubissa, L. (2015). El "género", Foucault y algunas tensiones feministas. Estudios de Filosofía, 52(52), 29-43. https://doi.org/10.17533/udea.ef.n52a03

Quijano, A. (1992). Colonialidad Modernidad Racionalidad. Perú Indígena, 13(29), 11-20.

Restrepo, E. y Rojas, A. (2010). Inflexión Decolonial: Fuentes, Conceptos y Cuestionamientos. Popayán: Universidad del Cauca.

Shiva, V. (1995). Abrazar la vida. Mujer, ecología y desarrollo. Madrid: Hora y Horas

Shiva, V. (2001). El mundo en el límite. En W. Hutton y A. Giddens (coords.), El Límite. La Vida En El Capitalismo Global (pp. 1-11). Tusquets

Varea, S. y Zaragocin, S. (Comps.) (2017). Feminismos y buen vivir: Utopías decoloniales. Cuenca: PYDLOS Ediciones.

Winder, N. y Torres, C. (2010). Dinámica de género y cultura en salud en América Latina y el Caribe. Organización Panamericana de la Salud. https://iris. paho.org/bitstream/handle/10665.2/5672/GDR-Dinamica-de-genero-y-cultura. pdf? sequence $=1$ \&isAllowed $=y$ 